Eugene A. Pilotte

Rutgers University-Camden

Frederic P. Sterbenz

University of Wyoming

\section{Sharpe and Treynor Ratios on Treasury Bonds*}

\section{Introduction}

Sharpe (1966) introduces the reward-to-variability ratio, more commonly referred to as the Sharpe index, Sharpe measure, or Sharpe ratio. For consistency of usage, we use the term Sharpe ratio in this paper. For any risky asset or portfolio of assets, the Sharpe ratio is defined as the ratio of the excess return to the standard deviation of that return. Treynor (1965) provides an alternative reward-to-risk ratio. The Treynor ratio is the ratio of the excess return to the systematic risk of that return. Both the Sharpe and Treynor ratios can be based on either ex ante or ex post excess returns and standard deviations (see Sharpe 1994). Ex post ratios are most useful for evaluating past investment performance. To the extent that historical results have predictive ability, ex post ratios are also useful for making decisions about future portfolio allocations. However, for decision-making purposes ex ante ratios are preferred.

Prior empirical studies focus on ex post Sharpe and Treynor ratios and typically limit their attention to common stocks. If bonds are included, the

* We thank an anonymous referee, Mukarram Attari, seminar participants at Rutgers University, and participants in the 2001 Annual Meeting of the Financial Management Association International for many valuable comments and suggestions. All errors are our own. Contact the corresponding author, Eugene A. Pilotte at pilotte@camden.rutgers.edu.

(Journal of Business, 2006, vol. 79, no. 1)

(C) 2006 by The University of Chicago. All rights reserved. 0021-9398/2006/7901-0007\$10.00
We challenge asset pricing theory with numerous stylized facts regarding risk and return on U.S. Treasury securities. Most striking is our finding that reward/risk ratios vary inversely with maturity and are incredibly high for short-term bills. Apparently investors would do much better engaging in highly leveraged investments in bills instead of purchasing longmaturity bonds or common stocks.

Simulations of estimated three-factor affine term structure models do not replicate the high ratios of reward to risk for bills. Other results include business cycle patterns in risk premiums, volatility, and the reward to volatility that vary with maturity. 
analysis is limited to corporate bonds. ${ }^{1}$ Treasury securities are incorporated in these studies only through the choice of the risk-free security used to calculate excess returns. ${ }^{2}$ However, Treasury securities are risk free only if they are held to maturity. Otherwise, they have uncertain returns that, like stock returns, can be evaluated with Sharpe and Treynor ratios.

This paper fills a gap in the existing literature by examining both types of reward-to-risk ratios, the Sharpe ratio and the Treynor ratio, on U.S. Treasury securities. We use a simple empirical model, based on findings from the literature on the predictability of asset returns, to estimate monthly conditional means and conditional volatilities (standard deviations) of excess returns on bills and bonds of different maturities over the period 1959-97. Ratios of conditional means to conditional volatilities provide time series of estimates of ex ante reward-to-risk ratios. These time series enable us to examine two major issues, the impact of maturity on the ratios and the existence of time variation in the ratios.

The goal of this paper is not to test a particular model of asset pricing. Rather, it is to provide a general exploration of bill and bond returns that documents empirical regularities regarding reliable estimates of ex ante reward-to-risk ratios and their components. Such an examination is of interest for several reasons. First, and most obvious, reward-to-risk ratios have implications for portfolio selection. The intention of Sharpe and Treynor ratios is to rank assets according to their risk-return characteristics. We find reward-to-risk ratios on bills and bonds decline with maturity, with long-term bonds having ratios similar to those on equity securities. Second, Fama and French (1989) show that excess returns on long-maturity assets vary inversely with the business cycle, but it is not known whether this business cycle variation is attributable to changing risk or changing reward to risk. We find that reward-to-risk ratios, not conditional volatilities, follow the business cycle pattern identified by Fama and French. Third, the impact of shortening maturity on the countercyclical variation identified by Fama and French is not known. We find that this countercyclical variation in expected returns and reward-to-risk ratios is limited to bond maturities of 2 years or more. Fourth, a common practice in empirical tests and theoretical models of the term structure is to assume that reward-to-risk ratios are constant and bill and bond returns are driven entirely by changing volatility. ${ }^{3}$ For longmaturity assets (maturity of 2 years or more), we find that time variation

1. For instance, Sharpe (1966) examines ex post Sharpe and Treynor ratios on 34 stock mutual funds over 1954-63. Hodges, Taylor, and Yoder (1997) examine the influence of holding period during 1926-93 on Sharpe ratios for stocks and corporate bonds.

2. Sharpe (1966) uses the 10-year government bond. Hodges et al. (1997) use the 30-day T-bill.

3 . This is a standard assumption in continuous-time affine models of the term structure of interest rates. For examples, see Cox, Ingersol, and Ross (1985) and Dai and Singleton (2000). For examples in the empirical bond pricing literature, see Fama (1976), Lauterbach (1989), and Klemkosky and Pilotte (1992). For examples using stock returns, see Campbell (1987), French, Schwert, and Stambaugh (1987), and Glosten, Jaganathan, and Runkle (1993). 
in conditional mean excess returns more closely mirrors the variation in reward-to-risk ratios than it does variation in conditional volatility. For short-maturity assets, conditional means more closely mirror conditional volatility. Fifth, Duffee (2002) extends the class of affine term structure models to allow variation in both risk and the reward to risk. We find that simulations of Duffee's three-factor models do not reproduce the pattern of Sharpe ratios we find in the data. Reproducing this pattern represents a challenge for future term structure modeling. Finally, it is widely recognized that all long-term assets contain a term/maturity premium. Thus, our results have implications for other risky assets with fixed maturity dates.

The remainder of this study is organized as follows. Section II describes the data and the empirical methodology used to estimate Sharpe ratios. Section III presents summary statistics regarding Sharpe ratios on bills, bonds, and stocks and documents the impact of changing maturity on Sharpe ratios. Section IV examines variation in Sharpe ratios and their components over the business cycle. Section V presents a methodology for estimating conditional Treynor ratios and discusses results of that estimation. Section VI presents Sharpe ratios produced by simulations of three-factor essentially affine models of the term structure of interest rates. Section VII concludes.

\section{Sharpe Ratios: Methodology and Data}

\section{A. Empirical Methodology}

For any risky asset or portfolio, the Sharpe ratio is defined as the ratio of the excess return to the standard deviation of that return. We define the excess return on a risky asset as the difference between the 1-month holdingperiod return on the risky asset and the return on a U.S. Treasury bill expiring at the end of the month. This excess return is denoted $\mathrm{XR}_{t}$. To calculate an unconditional, ex post Sharpe ratio we follow the standard procedure of dividing the mean value of $\mathrm{XR}_{t}$ for the sample period by the standard deviation of $\mathrm{XR}_{t}$ for that period. Thus, the ex post Sharpe ratio is

$$
\text { Ex post Sharpe ratio }=\frac{\frac{1}{T} \sum_{t=1}^{T} \mathrm{XR}_{t}}{\mathrm{SD}\left(\mathrm{XR}_{t}\right)},
$$

where $\mathrm{SD}\left(\mathrm{XR}_{t}\right)$ denotes the standard deviation of $\mathrm{XR}_{t}$. Based on the standard deviation of the time series $\mathrm{XR}_{t}$, this is the reward-to-risk ratio, expressed in simple terms. For each portfolio examined, we calculate one ex post Sharpe ratio using our time series of excess returns.

The advantage of the ex post Sharpe ratio is ease of calculation. There are three disadvantages to this simple procedure. First, it is backward 
rather than forward looking. Thus, ex post Sharpe ratios are most useful for evaluating past investment performance. They are useful for making decisions about future portfolio allocations only to the extent that historical averages have predictive ability. Second, this simple procedure ignores any predictable variation in expected returns and volatilities. If some of the variation in $\mathrm{XR}_{t}$ is predictable, the sample mean and standard deviation generally will mistate the expected return and risk to holding the asset for any given month. Third, because this ex post procedure assumes that expected returns, volatilities, and Sharpe ratios are constant over time, it provides no information regarding the sources of time varying risk premiums.

The ex ante total risk to holding an asset is the unpredictable component of the return to holding that asset. Thus, we begin our estimation of ex ante Sharpe ratios by decomposing monthly excess returns into predictable and unpredictable components. A straightforward way to do so is to model a portfolio's excess return and volatility conditional on beginning of period information. The ratio of conditional mean to conditional standard deviation provides a conditional ex ante Sharpe ratio for each month.

In modeling excess returns and volatilities, our primary goal is to identify a substantial amount of the predictable variation in returns. A powerful instrument for identifying the predictable variation in bond returns is the bond's own yield spread, defined to be the difference between the bond's yield to maturity and the return on a Treasury bill with 1 month to maturity. Fama (1990) shows that the yield spread contains the market's estimate of the ex ante risk premium, so it reflects any predictable variation in that premium. In addition to the ex ante premium, the yield spread also contains a forecast of the expected change in the 1 -month bill rate. Thus, if the 1-month rate is mean reverting, a yield spread of fixed size will imply a larger ex ante premium when the 1-month rate is high versus low. So our examination of bill and bond portfolios is based on the following generalized autoregressive conditional heteroscedasticity, or GARCH, $(1,1)$ model:

$$
\begin{gathered}
\mathrm{XR}_{t}=\alpha_{0}+\alpha_{1} \operatorname{TBILL}_{t}+\alpha_{2}\left(\mathrm{YIELD}_{t}-\mathrm{TBILL}_{t}\right)+\varepsilon_{t} \\
\sigma_{\varepsilon, t}^{2}=\gamma_{0}+\gamma_{1} \varepsilon_{t-1}^{2}+\gamma_{2} \sigma_{\varepsilon, t-1}^{2}
\end{gathered}
$$

where TBILL $_{t}$ is the 1-month rate and YIELD ${ }_{t}$ is the yield to maturity on the long-term bond. The excess return is observed at the end of month $t$, while the explanatory variables are observed at the beginning of month $t$. The unpredictable component of the bill or bond portfolio return, $\varepsilon_{t}$, is from a distribution with a mean of zero and conditional variance $\sigma_{\varepsilon, t}^{2}$. This regression system is simple and yet captures the anticipated component of 
the ex post excess return. It also allows the ex ante risk to vary over time, as the conditional variance, $\sigma_{\varepsilon, t}^{2}$, changes from month to month. The yield spread reflects the risk premium embedded in long-term bonds and TBILL $_{t}$ adjusts for mean reversion in the 1-month rate.

For comparison purposes, we also estimate Sharpe ratios on equalweighted and value-weighted portfolios of New York Stock Exchange (NYSE) stocks. The value-weighted portfolio is representative of large firm stocks, while the equal-weighted portfolio is more representative of small firm stocks. Based on results from the literature on the predictability of stock returns, we estimate the following model of conditional excess returns and volatilities for stocks:

$$
\begin{gathered}
\mathrm{XR}_{t}=\alpha_{0}+\alpha_{1} \mathrm{TBILL}_{t}+\alpha_{2} \operatorname{VWDYLD}_{t}+\varepsilon_{t} \\
\sigma_{\varepsilon, t}^{2}=\gamma_{0}+\gamma_{1} \varepsilon_{t-1}^{2}+\gamma_{2} \sigma_{\varepsilon, t-1}^{2}
\end{gathered}
$$

where VWDYLD Vis $_{t}$ the dividend yield on the value-weighted index of NYSE stocks, calculated over the 12 months prior to month $t^{4}$

Each GARCH $(1,1)$ regression produces a set of coefficients and a time series of standard deviations. The coefficients are used to construct fitted values for the excess returns, which are monthly conditional estimates of the ex ante risk premium. The time series of conditional standard deviations are used as the denominators of the Sharpe ratio. By using fitted values for the expected excess returns, $\hat{\mathrm{X}} \mathrm{R}_{t}$, and conditional standard deviations, $\hat{\sigma}_{\varepsilon, t}$, we form a time series of ex ante Sharpe ratios according to $\mathrm{SR}_{t}=\hat{\mathrm{XR}}_{t} / \hat{\sigma}_{\varepsilon, t}$.

\section{B. Data}

All data for our study is from the Center for Research of Security Prices (CRSP). Treasury bill and bond returns are from the CRSP Fama Files. Stock return data are from the CRSP Monthly Stock Master file. We examine two bill, five bond, and two stock portfolios. The two bill portfolios, denoted Bill3 and Bill6, each consist of a single bill having 3 months or 6 months to maturity, respectively. The five bond portfolios are denoted Bond1 through Bond5. Bond1 contains all Treasury bonds having maturity of 1 year or less. Bond 2 consists of bonds having maturity of more than 1 year but less than 2 years. Other bond portfolios are similarly defined, with Bond5 consisting of bonds having maturity of

4. Prior evidence of the predictive power of the dividend yield appears in Fama and French (1989), Cochrane (1991), Hodrick (1992), Whitelaw (1994), and Pesaran and Timmerman (1995). Campbell (1987), Whitelaw (1994), and Pesaran and Timmerman (1995) find that stock returns are related to the level of nominal interest rates. Based on these prior studies, we expect stock excess returns to be positively related to the dividend yield and negatively related to the bill rate. 
4-5 years. We are able to exactly match the yields for the bill portfolios to the bill maturity since they consist of single bills. This is not possible with bond portfolios. Yields for the bond portfolios are yields for Fama-Bliss discount bonds. The yield is for the discount bond at the upper bound of maturity allowed in a portfolio. For example, the yield matched to Bond 3 is the yield on a discount bond having 3 years to maturity. The stock portfolios are the equal-weighted and value-weighted portfolios of NYSE stocks, denoted EWSTK and VWSTK, respectively. Dividend yields are calculated with data from the CRSP Monthly Stock Master file using the procedure of Fama and French (1988). All returns are expressed as monthly continuously compounded returns.

\section{Results of Sharpe Ratio Estimation}

We report the results of the estimation of the regression systems (2) and (3) in table 1 . The results document predictable variation in all bill, bond, and stock portfolio excess returns. For all bills and bonds, the yield spread is statistically significant with a $t$-statistic of 3.96 or greater, while the TBILL $_{t}$ is positive and significant only for the bills and bonds with maturities of less than 1 year. For both stock portfolios, the results are consistent with prior findings reported in the prediction literature. Equalweighted and value-weighted stock excess returns are negatively related to the nominal 1-month rate and positively related to the prior year dividend yield. While we find evidence of predictable variation in returns for all of our portfolios, the regression $R^{2}$ values range from 0.03 to 0.21 , so much of the variation in ex post returns is unpredictable.

The GARCH coefficients, $\gamma_{1}$ and $\gamma_{2}$ are always positive and statistically significant, documenting variation in conditional risk for all bill, bond, and stock portfolios. The sum $\left(\gamma_{1}+\gamma_{2}\right)$ is often close to 1 , a common finding in applications of $\operatorname{GARCH}(1,1)$ modeling of interest rates. This implies that current shocks affect volatility into the indefinite future. ${ }^{5}$

Table 2 contains means and standard deviations of ex post risk premiums on bills, bonds, and stocks for the full sample. Ex post Sharpe ratios, calculated by dividing the mean ex post premium by its standard deviation, are also reported. While each ex post value for a portfolio is unique, we have time series of ex ante conditional means, conditional standard deviations, and Sharpe ratios. Table 2 reports sample means for these ex ante variables. ${ }^{6}$

5. For the 1-month T-bill rate, Gray (1996) finds that modeling the interest rate process with a regime-switching model produces sums of $\gamma_{1}$ and $\gamma_{2}$ that are reliably less than 1 .

6 . Recall that the ex ante Sharpe ratio is calculated monthly by dividing the ex ante premium by the ex ante standard deviation. The mean Sharpe ratio is then calculated by averaging ex ante Sharpe ratios across periods. The mean Sharpe ratio generally will differ from the Sharpe ratio obtained by dividing the mean ex ante premium by the mean ex ante standard deviation. 
TABLE 1 Estimation of Monthly Ex Ante Excess Returns and Ex Ante Volatilities, March 1959-December 1997 ( $t$-Statistics in Parentheses)

\begin{tabular}{lccccccc}
\hline Portfolio & \multirow{2}{*}{$\alpha_{0}$} & $\alpha_{1}$ & $\alpha_{2}$ & $\gamma_{0}$ & $\gamma_{1}$ & $\gamma_{2}$ & $R^{2}$ \\
\hline \multicolumn{7}{c}{ A. GARCH } \\
(1, 1) Model for Treasury Bills and Bond Portfolios: \\
\multicolumn{7}{c}{$\mathrm{XR}_{t}=\alpha_{0}+\alpha_{1} \mathrm{TBILL}_{t}+\alpha_{2}\left(\mathrm{YIELD}_{t}-\mathrm{TBILL}_{t}\right)+\varepsilon_{t}$} \\
\hline Bill3 & -.0001 & .0745 & 1.0592 & .0000 & .2880 & .6365 & .21 \\
& $(-2.08)^{*}$ & $(6.69)^{* *}$ & $(16.81)^{* *}$ & $(5.61)^{* *}$ & $(6.95)^{* *}$ & $(18.87)^{* *}$ & \\
Bill6 & $-.0003 *$ & .1222 & 1.2181 & .0000 & .2462 & .7852 & .08 \\
& $(-2.78)$ & $(4.13)^{* *}$ & $(7.99)^{* *}$ & $(2.45)^{*}$ & $(7.93)^{* *}$ & $(35.64)^{* *}$ & \\
Bond1 & -.0006 & .1262 & 1.0593 & .0000 & .2053 & .8113 & .07 \\
& $(-2.90)^{* *}$ & $(3.01)^{* *}$ & $(6.69)^{* *}$ & $(1.62)$ & $(5.81)^{* *}$ & $(29.24)^{* *}$ & \\
Bond2 & -.0013 & .2301 & 1.7226 & .0000 & .1717 & .8339 & .04 \\
& $(-1.93)$ & $(1.72)$ & $(4.67)^{* *}$ & $(2.89)^{* *}$ & $(5.94)^{* *}$ & $(32.21)^{* *}$ & \\
Bond3 & -.0020 & .2900 & 2.1309 & .0000 & .1580 & .8472 & .03 \\
& $(-1.69)$ & $(1.30)$ & $(4.21)^{* *}$ & $(3.35)^{* *}$ & $(6.34)^{* *}$ & $(39.64)^{* *}$ & \\
Bond4 & -.0024 & .2501 & 2.5329 & .0000 & .1491 & .8554 & .03 \\
& $(-1.53)$ & $(.87)$ & $(4.31)^{* *}$ & $(3.50)^{* *}$ & $(6.00)^{* *}$ & $(41.34)^{* *}$ & \\
Bond5 & -.0029 & .2738 & 2.6529 & .0000 & .1255 & .8757 & .03 \\
& $(-1.56)$ & $(.81)$ & $(3.96)^{* *}$ & $(3.41)^{* *}$ & $(6.48)^{* *}$ & $(53.59)^{* *}$ & \\
\hline
\end{tabular}

B. GARCH $(1,1)$ Model for Stock Portfolios:

$\mathrm{XR}_{t}=\alpha_{0}+\alpha_{1} \mathrm{TBILL}_{t}+\alpha_{2} \mathrm{VWDYLD}_{t}+\varepsilon_{t}$ $\sigma_{\varepsilon, t}^{2}=\gamma_{0}+\gamma_{1} \varepsilon_{t-1}^{2}+\gamma_{2} \sigma_{\varepsilon, t-1}^{2}$

\begin{tabular}{lllccccc}
\hline VWSTK & -.0035 & -3.7030 & .6472 & .0001 & .0779 & .8558 & .03 \\
& $(-.43)$ & $(-3.46)^{* *}$ & $(2.54)^{*}$ & $(2.02)^{*}$ & $(2.66)^{* *}$ & $(19.07)^{* *}$ & \\
EWSTK & -.0074 & -4.5891 & .8894 & .0002 & .0698 & .8573 & .04 \\
& $(-.80)$ & $(-3.49)^{* *}$ & $(3.02)^{* *}$ & $(1.82)$ & $(2.72)^{* *}$ & $(14.78)^{* *}$ & \\
\hline
\end{tabular}

NoTE.-Portfolios are defined as follows. Bill3 and Bill6 are Treasury bills having maturities of 3 and 6 months, respectively. Bond portfolios are based on maturity intervals of 1 year. For instance, Bond 3 consists of Treasury bonds having a maturity greater than 2 years and less than or equal to 3 years. VWSTK is the value-weighted NYSE index and EWSTK is the equal-weighted NYSE index. $\mathrm{XR}_{t}$ is the portfolio excess return for month $t$, where month $t$ begins at time $t$ and ends at $t+1$. TBILL $t$ is the certain return

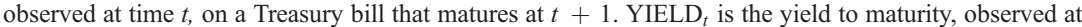
time $t$, on a discount bill or Fama-Bliss discount bond, where the maturity of the discount security is equal to the maximum possible maturity of the portfolio. For example, for Bond3, YIELD ${ }_{t}$ is the yield on a FamaBliss discount bond with a maturity of 3 years. VWDYLD $t$ is the dividend yield on the value-weighted index of NYSE stocks, calculated over the 12 months prior to month t. The sample consists of 466 monthly observations from March 1959 to December 1997.

* Significance at 0.05 level, two-tailed test.

** Significance at 0.01 level, two-tailed test.

Because our Sharpe ratios are based on monthly returns, they are smaller than Sharpe ratios based on annual returns. ${ }^{7}$

For each bill and bond portfolio reported in table 2, the mean ex ante Sharpe ratio is larger than the mean ex post Sharpe ratio, often substantially so. In particular, the mean ex ante Sharpe ratios for maturities of 1 year or less are about double the size of the corresponding ex post

7. For instance, if monthly returns were not autocorrelated, the means and standard deviations for annual returns would be expected to increase by factors of 12 and $\sqrt{12}$, respectively. Thus, Sharpe ratios based on annual returns should exceed those based on monthly returns by a factor of about $\sqrt{12}$. 


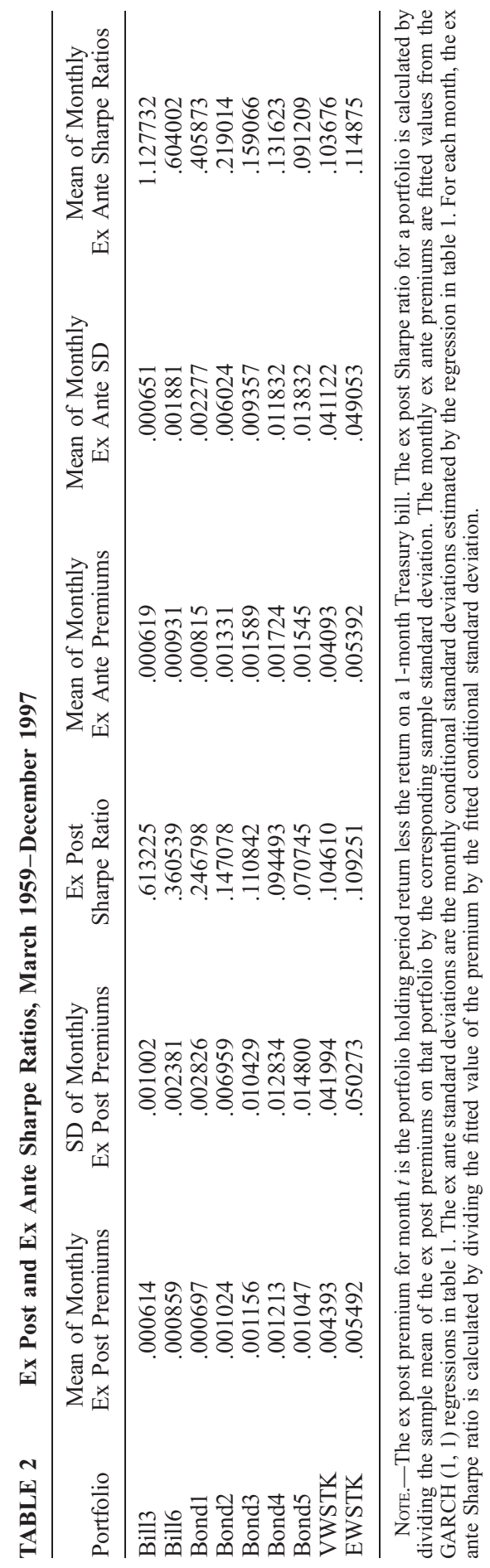


ratios. The gap between ex ante and ex post Sharpe ratios narrows as maturity increases, but a sizeable difference remains, even for the Bond5 portfolio. Thus, ex post Sharpe ratios appear to systematically understate the ex ante reward to bearing the risks associated with bills and bonds. There are two sources to this difference. First, the means of ex ante standard deviations are smaller than the ex post standard deviations. This occurs because the ex post standard deviation reflects all the variation in an ex post risk premium while the ex ante standard deviation reflects only the unpredictable component of that variation. Second, for bills and bonds, the mean fitted values for the ex ante premiums are greater than the mean ex post premiums. ${ }^{8}$ Contrary to the case of bills and bonds, the ex post and mean ex ante Sharpe ratios for stocks are of similar size. For each stock portfolio, a comparison of ex post and mean ex ante values indicates that the smaller mean ex ante volatility is offset by a smaller mean ex ante premium, resulting in a mean ex ante Sharpe ratio that is similar in size to the ex post Sharpe ratio.

Of particular interest is the pattern of results across maturities, which is the same for both ex post and ex ante Sharpe ratios. Sharpe ratios are very high for short-term bills and bonds and decrease as the bond maturity increases. The longest-term bond portfolio, Bond5, has ex post and ex ante Sharpe ratios similar to those for the equal- and value-weighted stock portfolios. The clear picture from table 2 is that both expected return and total risk increase with bond maturity, but risk increases at a faster rate than expected return. Thus, as increasing amounts of risk are taken the reward per unit of total risk drops.

The extremely high Sharpe ratios for the 3-month and 6-month bills indicate that they are particularly good investments in terms of the reward per unit of total risk. These ratios indicate that an investor can achieve better combinations of risk and return from a highly leveraged investment in the 3-or 6-month bill, than from investing a given dollar amount in either the 5-year bond or the stock portfolios. Faced with the ex ante Sharpe ratios in table 2, the investor should borrow at the 1-month rate and make a leveraged investment in the 3-month Treasury bill to achieve any desired level of risk or return. Leveraging the investment does not change the Sharpe ratio, so the reward-to-risk ratio is unaffected by taking more risk.

Consider, for example, an investment in common stocks. Conventional wisdom is that stocks involve greater risk than bonds but are good investments because they have a sizable risk premium and therefore higher expected excess returns. However, according to table 2, the ex ante Sharpe ratio for the 3-month bill is about 11 times as high as the

8. Maximum likelihood estimation of GARCH models does not constrain the estimated residuals to sum to zero, so the mean of the fitted premium does not necessarily equal the mean ex post premium. 
ex ante Sharpe ratio for the value-weighted stock portfolio. Since the ex ante standard deviations on stocks and 3-month bills are 0.041122 and 0.000651 , respectively, leveraging an investment in the 3-month bill 63 times produces the same risk as the stock portfolio but an expected excess return that is 11 times as high. Alternatively, by using a leverage factor of 7, approximately the same expected excess return could be obtained as for the stock portfolio but at one-eleventh the risk.

The obvious issue that our results raise is how the high Sharpe ratios for short-term bills and bonds can be consistent with the absence of arbitrage opportunities. One possible explanation is that the sources of systematic risk differ for short-term bills and long-term bonds. In multiple factor pricing models, the price per unit of risk need not be identical for all factors. We provide evidence regarding this explanation in Sections V and VI of this paper.

Even if the sources of risk are identical for all bills and bonds and we ignore the distinction between systematic and unsystematic risk, two potential barriers to arbitrage could permit divergence of reward-to-risk ratios. First, investors may face leverage constraints. With 3-month bills, the leverage factors required to reach the same expected risk premiums as unlevered investments in 5-year bonds and stocks are 3 and 7, respectively. The leverage factors required to reach the same risk levels as unlevered investments in 5-year bonds and stocks are 21 and 63, respectively. This kind of leverage is very high; thus, it may not be possible for the investor to leverage the 3-month bill sufficiently to get the same excess return or risk as a 5-year bond or stock portfolio. Second, there may be costs to a leveraged investment that are not reflected in the Sharpe ratio. Investors may not be able to borrow at the 1-month bill rate and they may face economically significant transactions costs. For instance, consider an investor with the quantity $W$ to invest. To leverage 10 times, the investor borrows $9 W$ and invests $10 \mathrm{~W}$ in a risky asset. Even if the investor can borrow at the 1-month bill rate, he must pay transactions costs on an investment of $10 \mathrm{~W}$. The transactions costs on the investment of $10 \mathrm{~W}$ are likely to be substantially higher than if only $W$ were invested. For example, if transactions costs are a constant proportion of the size of the investment, the total transactions cost is 10 times as high for an investment of $10 \mathrm{~W}$ as it is for an investment of $W$. Since returns on the leveraged investment are based on an investment of $W$, the higher transactions cost must also be compared to $W$. Even if the transactions cost on the initial investment of $W$ is a small proportion of excess returns, the use of leverage may multiply this proportion substantially. The result is that investors desiring high excess returns may have to use the long-term bond or stock portfolio and accept a lower Sharpe ratio. ${ }^{9}$

9. Luttmer (1996) points out that relationships among 1-period holding returns on Treasury bills of differing maturity are distorted by transactions costs, so that arbitrage conditions may not hold exactly. 
Thus, they have to accept a lower expected return per unit of risk to get a higher return on a fixed investment amount.

The high leverage factors suggested by our analysis are reminiscent of long-term capital management (LTCM) in the late 1990s. The experience of LTCM demonstrated that high leverage can leave an investor exposed to extreme risk if an out-of-model event occurs. Thus, the possibility of a low probability but extreme out-of-sample event may also have discouraged investors from making the highly leveraged investments suggested by our analysis.

\section{Sharpe Ratios and the Business Cycle}

\section{A. Examination of Peaks and Troughs}

Fama and French (1989) find that risk premiums on stocks and long-term corporate bonds are related to variables that track business conditions. They conclude that excess returns are high when economic conditions are weak and low when economic conditions are strong. They note that their results could be the result of either time-varying risks to investing in stocks and bonds or to time-varying reward to risk. The rationale for time-varying reward to risk is that, when times are bad and income is low, investors may be less willing to give up consumption and take on risk. Thus, a higher price of risk is required for markets to clear. ${ }^{10}$ This argument is relevant for all risky assets, even assets such as Treasury bonds that are exposed only to discount rate risk. ${ }^{11}$

In this section, we document the movements of Sharpe ratios over the business cycle. Our GARCH methodology is ideal for this examination, because it produces a time series of ex ante excess returns and volatilities from which we calculate ex ante Sharpe ratios on a monthly basis. Our focus on Treasury securities is advantageous for this examination, because it enables us to isolate the impact of changing business conditions on the price of discount rate risk from the impact on default risk. Also, since Treasury securities are available in a range of maturities, we are able to document the effect of changing maturity on the price of discount rate risk.

Table 3 reports Sharpe ratios at peaks and troughs in the business cycle. We use National Bureau of Economic Research (NBER) turning points taken from The Survey of Current Business (1998). A peak (trough) is considered to be the last observation in an expansion (recession). We

10. Ferson and Harvey (1991) state, "With decreasing relative risk aversion, high expected returns are required in recessions to induce investors away from current consumption and into risky investments." Campbell and Cochrane (1999) find that this effect is even stronger if consumption is habit forming.

11. For assets that also face default risk, Bernanke, Gertler, and Gilchrist (1996) suggest that rising default risk in recessions leads to higher default premiums. The higher risk premium raises the cost of borrowing and may deepen the recession. 


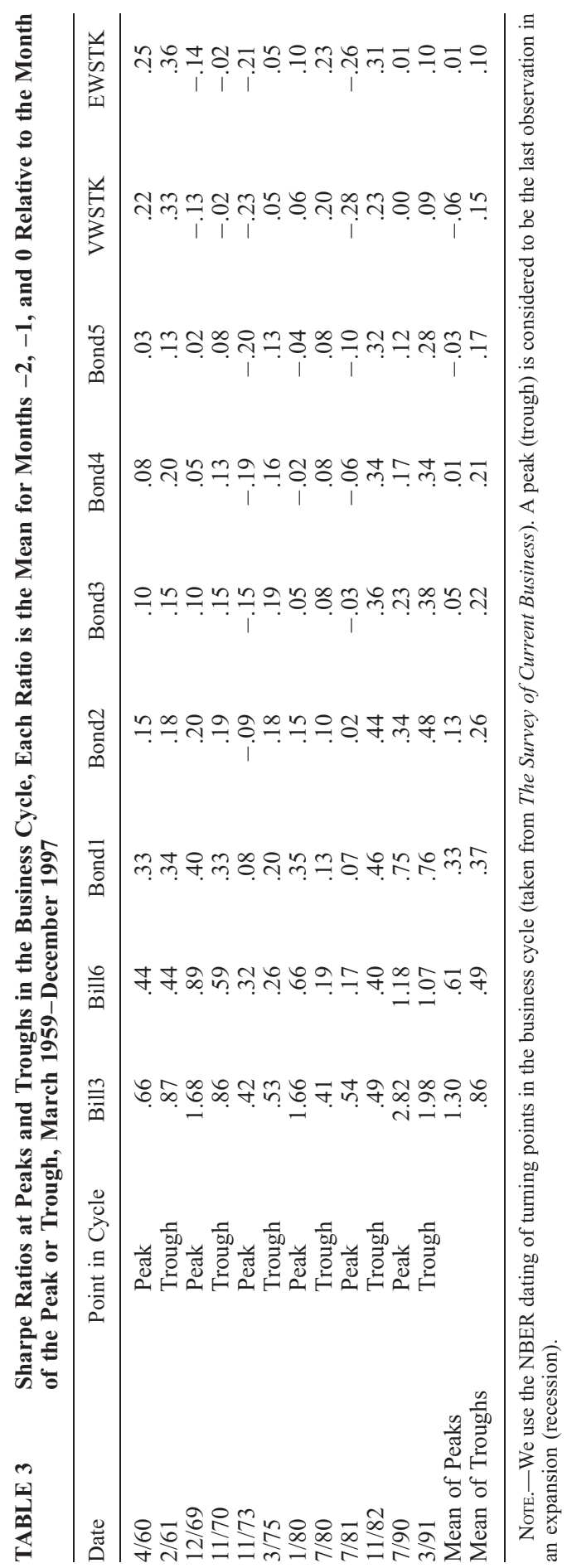


report mean Sharpe ratios for the final 3 months of each peak and trough. ${ }^{12}$ Our sample contains six peaks and six troughs. We also report the mean of the 18 peak months and the mean of the 18 trough months.

For each portfolio, we assess the statistical significance of the direction of change in the Sharpe ratio from peak to trough with a binomial test. The binomial probability of six successes from six draws is 0.0156 , while the probability of five or six successes from six draws is 0.1094 . Thus, the null hypothesis, that an increase in the Sharpe ratio is as likely as a decrease, is rejected at the 0.05 level (two-tailed test) only if the direction of change is the same for all six business cycles.

Examining table 3, the clear pattern that emerges for long-term bonds is that the Sharpe ratio at the trough is always higher than at the previous peak. This is true at each trough for the Bond3, Bond4, and Bond5 portfolios, so the null hypothesis, that the Sharpe ratio does not change from peak to trough, is rejected at the 0.05 level. The pattern for stock portfolios is the same as that for the long-term bonds. The Sharpe ratio is also higher on average at troughs than at peaks for the Bond1 and Bond2 portfolios. However, for both Bond1 and Bond2, in two instances the Sharpe ratio at the peak is higher than at the following trough, so the null hypothesis, that an increase is as likely as a decrease, is not rejected. For 3- and 6-month bills, the peaks on average show higher Sharpe ratios than the troughs, which is opposite the patterns for the long-term bonds and stocks. At troughs, Sharpe ratios for bills are generally, but not always, lower than at the prior peak. On average, from a reward-to-risk perspective, long-term bonds and stocks are more desirable at troughs than they are at peaks. Bills are more desirable at peaks than they are at troughs. However, while the binomial test rejects the null hypothesis of no change in the Sharpe ratio from peak to trough for the Bond3, Bond4, Bond5, and stock portfolios, the null hypothesis is not rejected for the Bill3, Bill6, Bond1, or Bond2 portfolios.

Some of the Sharpe ratios reported in table 3 are negative, which implies a negative ex ante risk premium. Sharpe ratios of changing sign are consistent with Fama and French (1993), who conclude that the empirical relation between bond excess returns and the spread between long-term and short-term yields predicts that the sign of excess returns changes over time. They are also consistent with Duffee (2002), who argues that reproducing the time-series behavior of bond excess returns requires a term structure model that permits the sign of expected excess returns to change over time.

Figure 1 is a graph of the Sharpe ratio on the Bond 4 portfolio over time. In this graph, vertical solid and dashed lines indicate the months of peaks and troughs, respectively. The time intervals from peaks to troughs generally are short relative to the time intervals from troughs to peaks.

\footnotetext{
12. The results are similar if we limit our analysis to the final month of each peak and trough.
} 


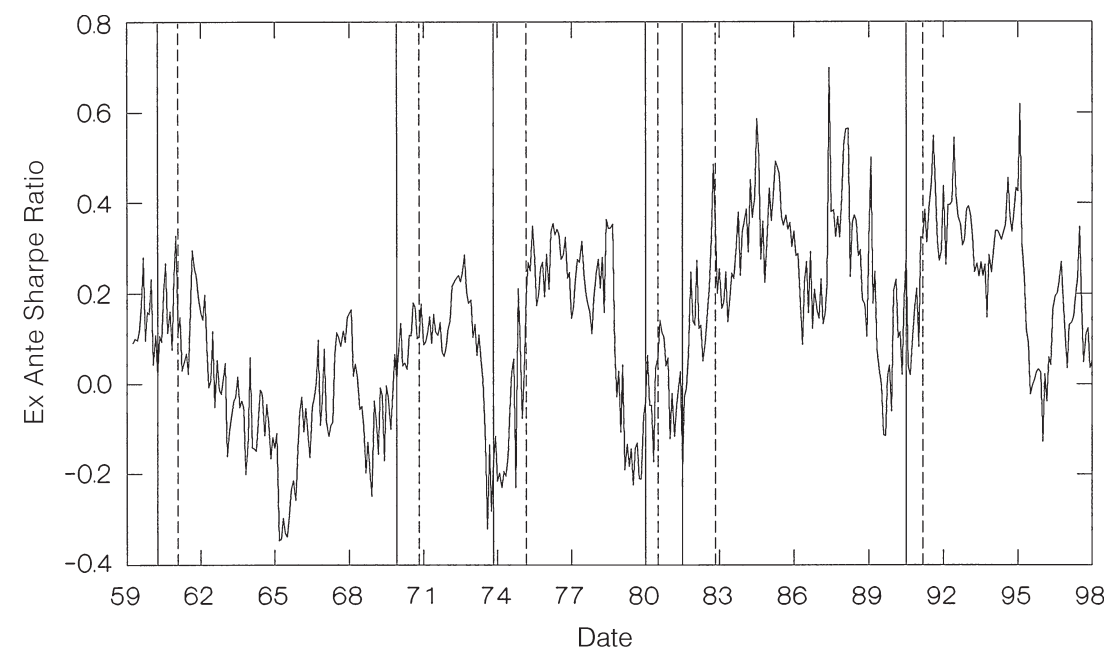

FIG. 1.-The ex ante Sharpe ratio on long-maturity bonds and the business cycle. The figure is a graph of the time series of Sharpe ratios estimated for a portfolio of U.S. Treasury bonds having maturities greater than 3 years and less than or equal to 4 years. The vertical solid and dashed lines indicate the months of business cycle peaks and troughs, respectively. The sample consists of 466 monthly estimates from March 1959 to December 1997.

The graph shows how much the Sharpe ratio varies over time, as well as how it relates to peaks and troughs. Clearly, for the Bond4 portfolio, the peaks in the business cycle are among the low points for the Sharpe ratio. However, there is also substantial variation in the Bond4 Sharpe ratio during each expansion and recession.

It is also interesting to look at the two components of the Sharpe ratio, the conditional mean excess return and conditional standard deviation, at business cycle peaks and troughs. For these variables, we report means for the final 3 months of each peak and trough in table $4 .{ }^{13}$ In general, the conditional means share the same business cycle pattern as the Sharpe ratios. For bonds and stocks, conditional mean excess returns are high at troughs and low at peaks. For bills, there is no obvious business cycle pattern. In contrast to Sharpe ratios and conditional means, conditional standard deviations exhibit no obvious business cycle pattern. For each bill, bond, and stock portfolio, the reported mean volatility for all trough months is greater than the mean volatility for all peak months. However, when individual peaks and troughs are compared, this pattern holds up only for the two stock portfolios, for which there are 11 instances where the volatility increases from peak to trough and 1 instance where the volatility decreases. In contrast to stocks, for the five bond portfolios, conditional volatility declines from peak to trough 16 times, increases

13. The results are similar if we limit our analysis to the final month of each peak and trough. 


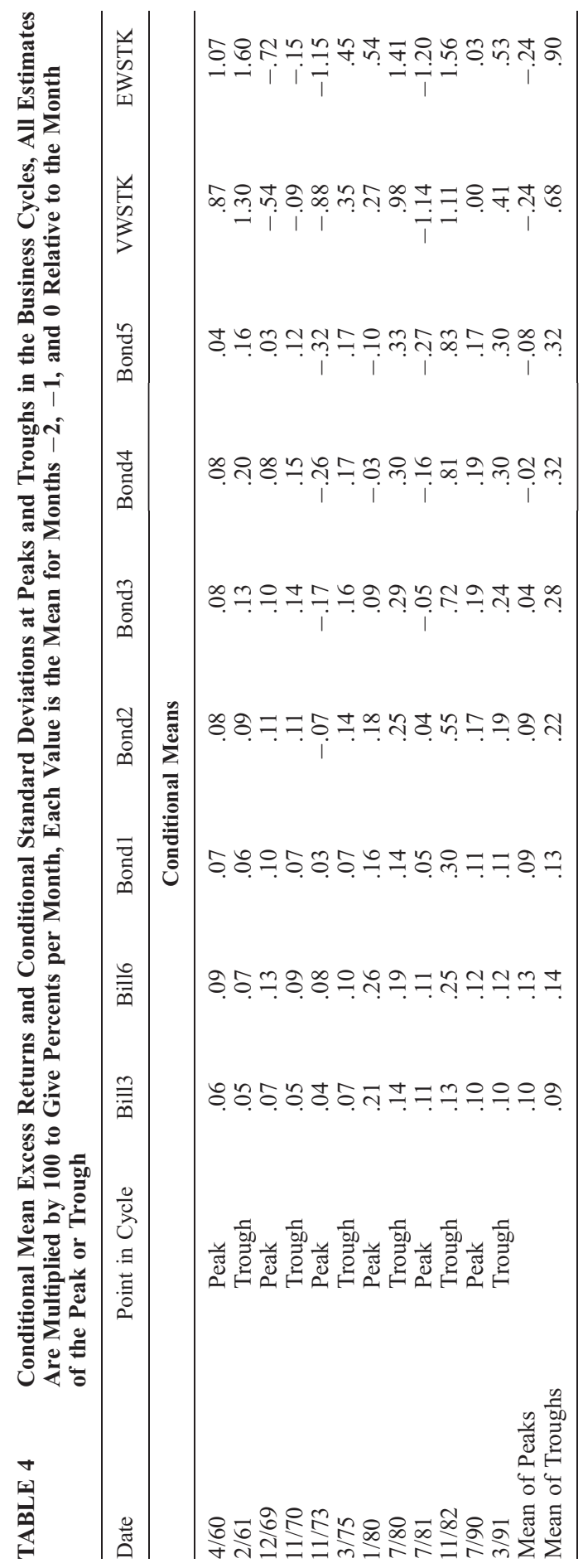




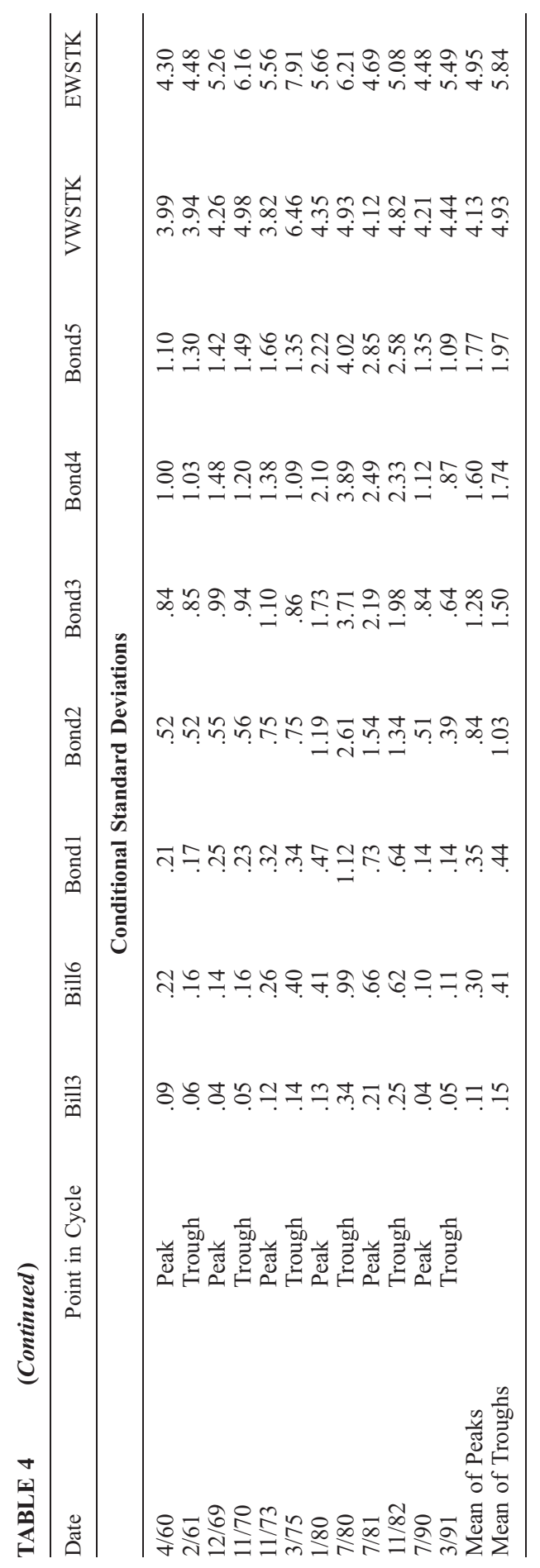




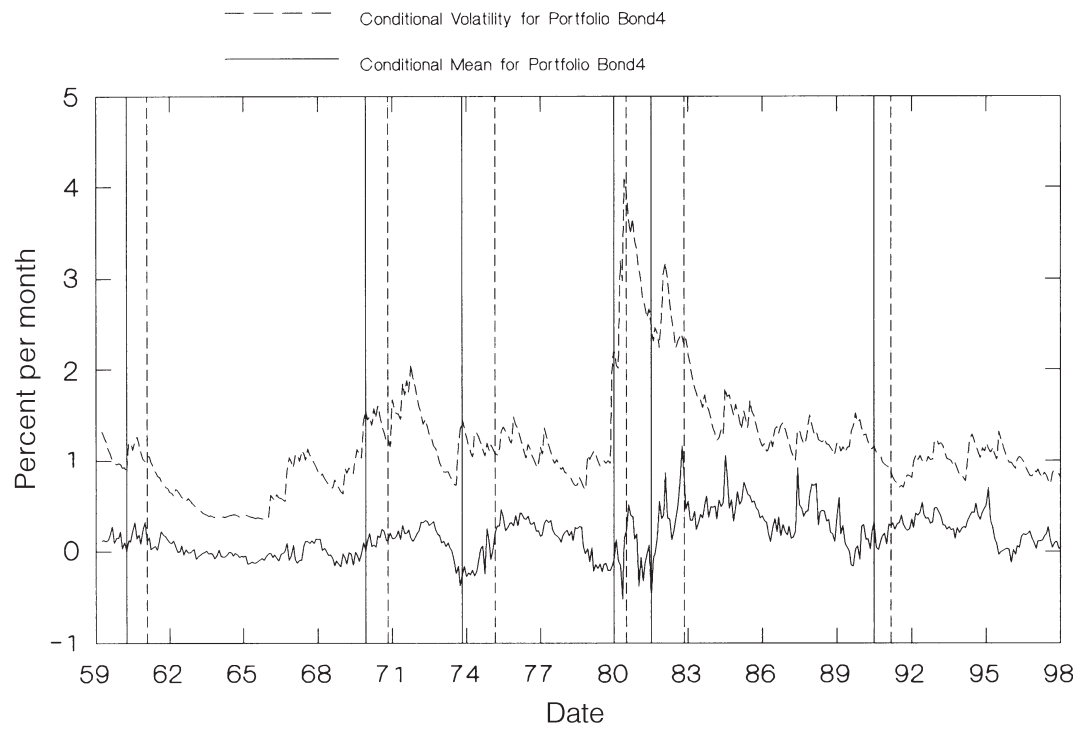

FIG. 2.-Time series of conditional means and conditional standard deviations for the Bond4 portfolio. The Bond4 portfolio consists of U.S. Treasury bonds having maturities greater than 3 years and less than or equal to 4 years. The vertical solid and dashed lines indicate the months of business cycle peaks and troughs, respectively. The sample consists of 466 monthly estimates of each variable from March 1959 to December 1997.

11 times, and exhibits no change 3 times. For the two bills, conditional volatility increases in nine instances and decreases in three. Care must be exercised in generalizing too much from an examination of only six business cycles, but the results reported in tables 3 and 4 are inconsistent with the idea that the business cycle pattern exhibited by excess returns is driven by changing risk. Rather, this pattern appears to be attributable to changes in the reward to risk.

A potential concern is that modeling the volatility with a $\operatorname{GARCH}(1,1)$ model will smooth the time series of ex ante volatilities so much that the Sharpe ratios will inherit the business cycle pattern of excess returns by construction. In particular, the trough sometimes follows soon after the peak and the $\operatorname{GARCH}(1,1)$ process exhibits persistence. Nonetheless, we find that the volatility does change in short intervals. To illustrate that this is the case, figure 2 graphs the conditional mean and conditional standard deviation for the Bond4 portfolio over time. Both series exhibit substantial variation over time, with the volatility series showing more variation than the conditional mean.

\section{B. Regression Analysis}

The patterns documented in tables 3 and 4 are suggestive but based on only a small subset of our data, 3 months from the beginning and 3 months from 
the end of each of the six business cycles in our sample. To use all the information in our data and better document the behavior of our estimates throughout the business cycle, we use a regression approach. For each portfolio in our sample, we estimate three regressions: one for the Sharpe ratio, one for the conditional volatility, and one for the conditional mean. Each estimated variable is regressed on two variables designed to identify the relative point in the business cycle (peak, recession, trough, or expansion). Both business cycle variables are based on the Conference Board's index of coincident indicators, which is designed to identify the dates of turning points in the business cycle. The coincident indicator is based on month-to-month percentage changes in four components: (1) employees on nonagricultural payrolls, (2) personal income, (3) industrial production, and (4) manufacturing and trade sales. ${ }^{14}$ Our first business cycle variable, denoted $\mathrm{PRIOR}_{t}$, is the percent change in the coincident index over the 12 months prior to month $t$. The term PRIOR $_{t}$ is calculated as the natural logarithm of the ratio of the month $t-1$ coincident index to the month $t-13$ coincident index. Our second business cycle variable, $\mathrm{POST}_{t}$, is the similarly calculated percent change in the coincident index over the 12 months from $t$ to $t+12$. Together, these two variables provide a simple method of dating the point in the business cycle at which any of our estimates is observed. A low value of $\mathrm{PRIOR}_{t}$ combined with a high value of $\mathrm{POST}_{t}$ indicates an observation near a trough. A high value of $\mathrm{PRIOR}_{t}$ combined with a low value of $\mathrm{POST}_{t}$ indicates an observation near a peak. High values of both variables indicate an observation in the middle of an expansion. Low values of both variables indicate an observation in the middle of a contraction.

For each portfolio, we document the relation of any time $t$ estimate, ESTIMATE $_{t}$, to the business cycle by estimating the following regression:

$$
\text { ESTIMATE }_{t}=\alpha_{0}+\alpha_{1} \text { PRIOR }_{t}+\alpha_{2} \text { POST }_{t}+\mu_{t} .
$$

We first estimate regression (4) where ESTIMATE is $_{t}$ the conditional Sharpe ratio estimated at time $t$. We separately estimate regression (4)

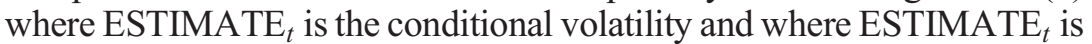

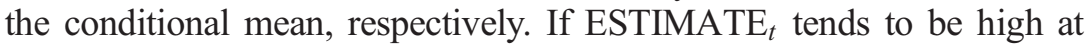
peaks and low at troughs, $\alpha_{1}$ will be positive and $\alpha_{2}$ will be negative. If ESTIMATE $_{t}$ tends to be low at peaks and high at troughs, $\alpha_{1}$ will be negative and $\alpha_{2}$ will be positive. If ESTIMATE $_{t}$ tends to be low (high) during expansions and high (low) during troughs, both $\alpha_{1}$ and $\alpha_{2}$ will be negative (positive). The intent of regression (4) is only to document the behavior of our estimates over the business cycle. No inferences regarding causation are implied.

Table 5 contains the results of estimating regressions based on (4). For the longer-term bonds and equal- and value-weighted stock portfolios, the

14. Details on the current and past construction of the coincident index and articles related to its use are available on the Conference Board's Web site at www.conference-board.org. 
TABLE 5 Coefficients from Regressions of Conditional Sharpe Ratios, Conditional Standard Deviations, and Conditional Mean Excess Returns on Variables That Track Business Conditions ( $t$-Statistics in Parentheses)

\begin{tabular}{|c|c|c|c|c|c|c|}
\hline & \multicolumn{2}{|c|}{$\begin{array}{l}\text { Coefficients for } \\
\text { Sharpe Ratios }\end{array}$} & \multicolumn{2}{|c|}{$\begin{array}{c}\text { Coefficients for } \\
\text { Standard Deviations }\end{array}$} & \multicolumn{2}{|c|}{$\begin{array}{l}\text { Coefficients for } \\
\text { Conditional Means }\end{array}$} \\
\hline & $\mathrm{PRIOR}_{t}$ & $\mathrm{POST}_{t}$ & $\mathrm{PRIOR}_{t}$ & $\mathrm{POST}_{t}$ & $\mathrm{PRIOR}_{t}$ & $\mathrm{POST}_{t}$ \\
\hline \multirow[t]{2}{*}{ Bill3 } & 5.5880 & -3.4413 & -.0089 & -.0060 & -.0025 & -.0057 \\
\hline & $(3.66)^{* *}$ & $(-2.22)^{*}$ & $(-10.42)^{* *}$ & $(-6.96)^{* *}$ & $(-2.91)^{* *}$ & $(-6.56)^{* *}$ \\
\hline \multirow[t]{2}{*}{ Bill6 } & 4.0097 & -.5646 & -.0282 & -.0160 & -.0032 & -.0074 \\
\hline & $(5.83)^{* *}$ & $(-.81)$ & $(-10.74)^{* *}$ & $(-6.01)^{* *}$ & $(-2.59)^{* *}$ & $(-5.96)^{* *}$ \\
\hline \multirow[t]{2}{*}{ Bond1 } & 1.9439 & .0875 & -.0292 & -.0201 & -.0030 & -.0032 \\
\hline & $(3.43)^{* *}$ & $(.15)$ & $(-9.93)^{* *}$ & $(-6.75)^{* *}$ & $(-2.37)^{*}$ & $(-2.52)^{*}$ \\
\hline \multirow[t]{2}{*}{ Bond2 } & -.3990 & .6161 & -.0615 & -.0405 & -.0094 & .0030 \\
\hline & $(-1.03)$ & $(1.56)$ & $(-9.64)^{* *}$ & $(-6.24)^{* *}$ & $(-3.74)^{* *}$ & (1.19) \\
\hline \multirow[t]{2}{*}{ Bond3 } & -1.1188 & .9823 & -.0871 & -.0512 & -.0160 & .0115 \\
\hline & $(-3.23)^{* *}$ & $(2.79)^{* *}$ & $(-9.66)^{* *}$ & $(-5.59)^{* *}$ & $(-4.73)^{* *}$ & $(3.34)^{* *}$ \\
\hline \multirow[t]{2}{*}{ Bond4 } & -1.5674 & 1.4696 & -.0971 & -.0598 & -.0203 & .0226 \\
\hline & $(-4.40)^{* *}$ & $(4.06)^{* *}$ & $(-9.78)^{* *}$ & $(-5.92)^{* *}$ & $(-4.71)^{* *}$ & $(5.14)^{* *}$ \\
\hline \multirow[t]{2}{*}{ Bond5 } & -1.8119 & 1.4398 & -.06663 & -.0294 & -.0238 & .0288 \\
\hline & $(-5.29)^{* *}$ & $(4.14)^{* *}$ & $(-6.14)^{* *}$ & $(-2.67)^{* *}$ & $(-5.03)^{* *}$ & $(6.01)^{* *}$ \\
\hline \multirow[t]{2}{*}{ VWSTK } & -.6651 & 4.1250 & -.1107 & -.0310 & -.0364 & .1699 \\
\hline & $(-3.20)^{* *}$ & $(19.51)^{* *}$ & $(-8.74)^{* *}$ & $(-2.41)^{*}$ & $(-4.35)^{* *}$ & $(20.01)^{* *}$ \\
\hline \multirow[t]{2}{*}{ VWSTK } & -.8196 & 4.1458 & -.1090 & -.0521 & -.0531 & .2088 \\
\hline & $(-3.65)^{* *}$ & $(18.19)^{* *}$ & $(-7.00)^{* *}$ & $(-3.29)^{* *}$ & $(-5.00)^{* *}$ & $(19.32)^{* *}$ \\
\hline
\end{tabular}

NoтE.- Sharpe ratios, standard deviations, and mean excess returns are conditional on information available at the beginning of month $t$. PRIOR $t$ and $\mathrm{POST}_{t}$ are the percentage changes in the coincident index of economic indicators for the 12 months preceding and following month $t$, respectively.

regression results confirm our conclusions from examining Sharpe ratios at peaks and troughs. The coefficients on $\mathrm{PRIOR}_{t}$ are reliably negative and those on $\mathrm{POST}_{t}$ are reliably positive, indicating that Sharpe ratios reach their maximum values near troughs and minimum values near peaks. For Bill3, the coefficients reverse sign, so contrary to long-term bonds, the Sharpe ratio on 3-month bills tends to be maximized at peaks and minimized at troughs. For the Bill6, Bond1, and Bond2 portfolios, one or both $t$-statistics on the coefficients are small, so the relation of Sharpe ratios on these maturities to the point in the business cycle is not as clear.

Perhaps the most striking regression results are those for conditional volatilities. Recall that our table 4 examination of volatilities at peaks and troughs identified no clear business cycle pattern. By using the additional information from months between the peaks and troughs, regression (4) is able to better characterize the business cycle pattern of conditional volatilities. For every portfolio, the coefficients on $\mathrm{PRIOR}_{t}$ and $\mathrm{POST}_{t}$ are reliably negative. These results indicate that volatilities for bills, bonds, and stocks peak during recessions but well before the trough. 
The regression results for conditional means complete the picture. Interestingly, the coefficients for bills and bonds of maturities of less than 1 year exhibit the same pattern as the coefficients for those portfolio's conditional volatilities. For stocks and long-term bonds, the coefficients exhibit the same pattern as the coefficients for those portfolio's Sharpe ratios. Thus, it appears that changes in risk are the predominant determinants of excess returns for short-maturity bills and bonds, while changes in the reward to risk are the predominant determinants of excess returns for longmaturity bonds and stocks.

Our results have implications for asset pricing models. For instance, it is common practice in affine term structure models and in some other pricing models to assume that the market prices of risk are constant so that innovations in ex ante volatilities are the sole determinants of innovations in risk premiums. Our results indicate that this assumption may be reasonable for Treasury securities having maturities of 1 year or less, because volatilities and conditional means of these maturities tend to peak at the same point in the business cycle. However, for longerterm bonds and for stocks, volatilities tend to peak prior to conditional means, so assuming that innovations in volatilities are the sole determinants of innovations in risk premiums for long-maturity assets is likely to lead to misleading inferences. In fact, Whitelaw (1994) also finds that volatility leads expected returns on the value-weighted stock portfolio. He offers this finding as a potential explanation for the mixed results of studies of the relation between excess returns and volatility on stocks.

We examine the robustness of our results to reasonable changes to the specification of regression (4). First, we change the time interval over which we calculate $\mathrm{PRIOR}_{t}$ and POST $t$ to 6 and 18 months, respectively. Second, we replace $\mathrm{POST}_{t}$ with the percent change in the index of leading indicators prior to month $t .{ }^{15}$ Third, we replace the right-hand side variables of regression (4) with financial market variables known to track business conditions. All changes in specification support the same conclusions as the results reported in table 5. We report results based on $\mathrm{PRIOR}_{t}$ and $\mathrm{POST}_{t}$, because they link our ex ante variables directly to a measure of business activity (the coincident index) that does not depend on financial market variables. ${ }^{16}$ Regressions with financial market

15. The leading index of economic indicators is based on 10 components: (1) hours worked in manufacturing industries, (2) initial claims for unemployment insurance, (3) manufacturers' new orders of consumer goods and materials, (4) vendor delivery performance, (5) manufacturers' new orders of capital goods, (6) building permits of new private housing, (7) changes in the Standard and Poor's 500 stock index, (8) the money supply, (9) the spread between the yield on 10-year Treasury bonds and the federal funds rate, and (10) an index of consumer expectations.

16. Components of the Index of Leading Indicators include the yield spread on 10-year Treasury bonds and the percent change in the Standard and Poor's 500 stock index. 
variables on both the left- and right-hand sides are more open to alternative interpretations and the possibility of spurious correlation.

\section{Treynor Ratios}

\section{A. The Source(s) of Systematic Risk for Bills and Bonds}

The Sharpe ratio is based on the total risk of an investment. Its use is most appropriate when an investor intends to place all (or nearly all) of his wealth in one security or portfolio. When an investor is considering the addition of an investment to a well-diversified portfolio, the Treynor ratio is more appropriate, because it is based only on systematic risk.

In constructing a Treynor ratio for bonds, the major issue is the source of systematic risk. Studies of stock returns assume that the source of systematic risk is a broad portfolio of common stocks, so the Treynor ratio is generally defined to be the risk premium divided by beta. However, the asset pricing literature in the bond area and stock area developed somewhat independently, and in the bond pricing literature, the focus is usually on some measure of discount rate risk. This is the idea behind the concept of duration. Models such as Cox, Ingersol, and Ross (1985) assume that the short-term rate of interest is the only state variable that determines the prices of default-free bonds. Other models assume that there are two (or more) state variables. In Brennan and Schwartz (1982), the second state variable is the rate on a long-term bond. An equivalent approach is to use the difference between the long and short rates as the second state variable. In Longstaff and Schwartz (1992), the second state variable is the volatility of the change in the short rate. We reserve discussion of three-factor models, which considerably complicate the analysis, for Section VI of this paper.

In a more recent paper, Elton (1999) provides some evidence regarding the sources of systematic risk in daily bill and bond returns during the period from July 1991 to December 1997. He finds that one factor captures almost all of the variation in the return pattern for maturities of 2 years or more and much of the variation in shorter maturity bonds. A second factor further explains return variation for short maturities but adds little explanatory power for long maturities. He finds that the dominant factor is not related to characteristics of the short rate but a long rate can serve as a reasonable proxy for this factor. Elton concludes that the return on a longterm bond is the best proxy for systematic risk in a one-state variable model of the term structure. If a second factor is added, he concludes that the best proxy for that factor is a bill return.

Elton's findings that returns on short- and long-maturity bonds are relatively independent are consistent with results reported by Balduzzi, Elton, and Green (2001). They find that announcements of economic news have statistically significant impacts on prices of 2-year notes, 10-year 
notes, and 30-year bonds that is independent of price changes on 3-month bills.

\section{B. Comparison of Alternative State Variable Proxies}

We evaluated three potential state variable proxies: the return on a 1-month bill, the excess return on the 5-year bond, and the excess return on the value-weighted stock index. We evaluated the 1-month bill and long bond because of the evidence presented by Elton (1999) and Balduzzi et al. (2001). We evaluated the stock index because it is the traditional measure of systematic risk when calculating the Treynor index for stocks.

A straightforward way to assess the importance of each potential state variable proxy is to regress portfolio holding period returns on innovations (unexpected changes, shocks, surprises) in each variable from monthbeginning to month-end. Regression $R^{2}$ values can be used to evaluate the ability of each innovation to capture the common variation in bond returns. Estimates of the innovations in the excess returns to the 5-year bond and value-weighted stock portfolios are the residuals from the $\operatorname{GARCH}(1,1)$ regressions (2) and (3), respectively, for the Bond5 and VWSTK portfolios. The following $\operatorname{GARCH}(1,1)$ regression provides estimates of the innovation in the 1-month bill rate from $t$ to $t+1$ :

$$
\begin{aligned}
& \Delta \mathrm{TBILL}_{t}=-\underset{(-8.62)}{0.0002}+0.4171 \underset{(13.27)}{\mathrm{FORSPREAD}} \mathrm{P}_{t} \\
& -0.0684 \operatorname{REVERT}_{t}+e_{t} \\
& \sigma_{e, t}^{2}=\underset{(3.60)}{0.0000001}+\underset{(5.92)}{0.1790 e_{t-1}^{2}}+\underset{(21.77)}{0.7644 \sigma_{e, t-1}^{2}},
\end{aligned}
$$

where $\Delta$ TBILL $_{t}$ is the change in the 1-month bill rate from $t$ to $t+1$; the forward rate spread, FORSPREAD ${ }_{t}$, is the difference between the implied 1-month forward rate 1 month ahead and TBILL $L_{t}$; and REVERT Ri $_{t}$ the difference between TBILL ${ }_{t}$ and its average for the full sample period. ${ }^{17}$ The numbers in parentheses are $t$-statistics. The forward rate spread contains an estimate of the expected change in the 1-month rate from $t$ to $t+$ 1 and is included in regression (5) to use the information in the yield curve to isolate the unpredictable variation of $\Delta \mathrm{TBILL}_{t}$ in the error term, $e_{t}$. The variable REVERT $_{t}$ is included to capture mean reversion in the 1-month bill rate. Because the error term, $e_{t}$, is the unpredictable component of $\Delta \mathrm{TBILL}_{t}, e_{t}$ represents the time- $t$ shock to the short rate process and $\sigma_{e, t}^{2}$ provides monthly ex ante estimates of time- $t$ short-rate risk.

In table 6 we report $R^{2}$ values from univariate and multivariate $\operatorname{GARCH}(1,1)$ regressions of ex post excess returns on the residuals that

17. The implied forward rate, observed at time $t$, is taken from the Fama Files on the CRSP Bond Tape. 


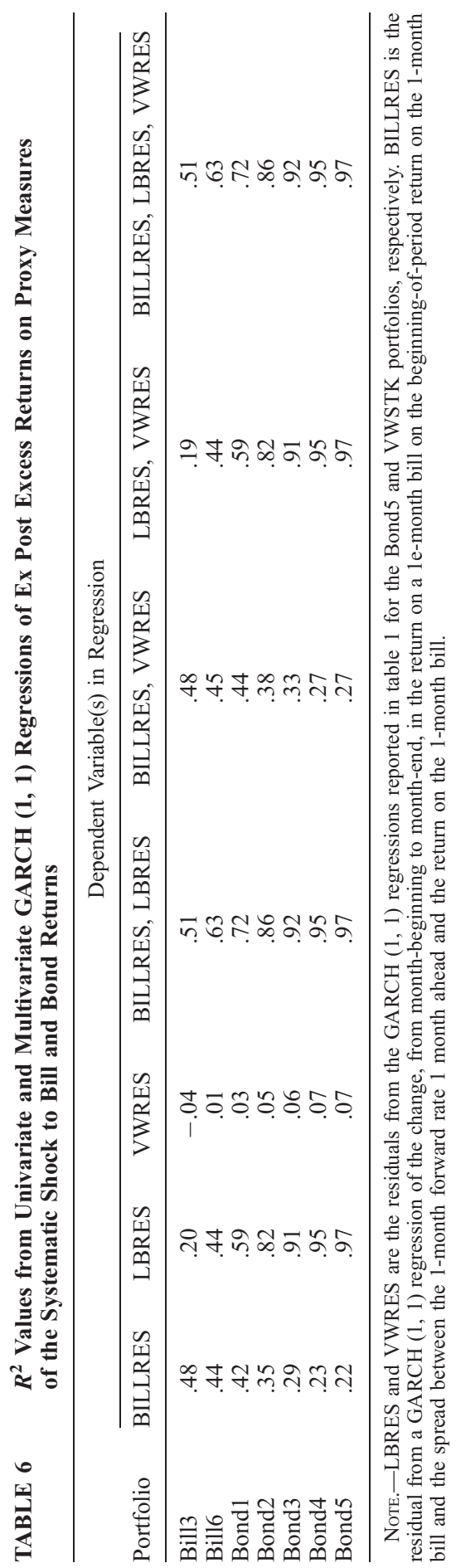


proxy for systematic state variable shocks. We denote the residuals for the long bond (Bond5 portfolio), 1-month bill, and value-weighted stock portfolios, respectively, as LBRES, BILLRES, and VWRES. Because residuals in GARCH regressions do not necessarily sum to zero, it is possible for the values of $R^{2}$ to be negative, and this does occur in one of our regressions. However, we find that the $R^{2}$ values reported in table 6 are similar to the $R^{2}$ values for ordinary least squares regressions, so they can be interpreted similarly. We report results for $\operatorname{GARCH}(1,1)$ estimation for consistency with other regressions reported in this paper.

The $R^{2}$ values from univariate regressions indicate that LBRES clearly dominates in terms of explanatory power for excess returns on maturities of more than 1 year, while BILLRES dominates only for the shortestmaturity bill. Moreover, the pattern of $R^{2}$ values across maturities indicates that LBRES is the better proxy for the systematic shock, as the $R^{2}$ increases with maturity for LBRES and decreases for BILLRES. Systematic shocks should have a greater impact on returns to longer maturity investments, since they affect the valuation of more cash flows that occur far into the future. The value-weighted stock portfolio appears to be a poor state variable proxy, as VWRES captures only a fraction of the variation in excess returns that is common to all our bill and bond portfolios. However, relative to the value-weighted stock portfolio, only the 3-month bill can be characterized as having zero systematic risk.

For maturities greater than 1 year, the $R^{2}$ values from multivariate regressions indicate that BILLRES adds only minimal explanatory power beyond that provided by LBRES. The reverse is true for the Bill3 portfolio, where LBRES adds little explanatory power beyond BILLRES. Both BILLRES and LBRES have additional explanatory power for the Bond 1 and Bill6 portfolios. For all but the Bill3 portfolio, VWRES adds explanatory power beyond BILLRES. Finally, VWRES has no explanatory power beyond that of LBRES.

As a check on the robustness of our results, we estimated (but do not report) the regressions in table 6 after replacing BILLRES with the regression (2) residual for the 3-month bill. Our conclusions are not affected by the choice of the proxy for the systematic shock to short-term rates.

Overall, the results in table 6 support the conclusions of Elton (1999) and Balduzzi et al. (2001). If a single instrument is to be used as a proxy for the systematic risk in bills and bonds, it should be a long-maturity bond. For maturities less than 1 year, a second state variable proxy, the 1 -month bill, provides additional explanatory power and can even be assumed to be the sole source of systematic risk for 3-month bills.

\section{Results of Estimation of Treynor Ratios for Bills and Bonds}

The results of the previous section indicate that the excess return on the Bond5 portfolio is the best proxy for the systematic risk associated with returns on Treasury bills and bonds. However, to check robustness of 
results and the implications of the state variable choice, we estimated ex ante Treynor ratios for all three state variable candidates.

The first step in the estimation is to decompose the total risk of each portfolio into systematic and unsystematic components. For each portfolio, the error term, $\varepsilon_{t}$, from regression (2) represents the month-tomonth random shock to the holding period return, and the conditional variance from that regression, $\sigma_{\varepsilon, t}^{2}$, represents the time-varying total risk for that portfolio. We decomposed the monthly shock and conditional variance of each portfolio into systematic and unsystematic components by using the estimated relation of that portfolio's shock to the proxy for the random systematic shock (BILLRES, LBRES, or VWRES) to bond prices. For each bill and bond portfolio, we estimated the sensitivity of the unanticipated component of the holding period return to the systematic shock with the following $\operatorname{GARCH}(1,1)$ regression:

$$
\begin{gathered}
\varepsilon_{t}=\beta_{0}+\beta_{1} e_{t}+\delta_{t} \\
\sigma_{\delta, t}^{2}=\gamma_{0}+\gamma_{1} \delta_{t-1}^{2}+\gamma_{2} \sigma_{\delta, t-1}^{2},
\end{gathered}
$$

where $\varepsilon_{t}$ is the residual from equation (2); $e_{t}$ is either BILLRES, LBRES, or VWRES; and $\beta_{1}$ is the sensitivity of the portfolio return to the systematic shock. Since $e_{t}$ and $\delta_{t}$ are uncorrelated by construction, the variance of $\varepsilon_{t}$ may be decomposed into two components. The first is the systematic component associated with $\beta_{1} e_{t}$, the second is the unsystematic component associated with $\delta_{t}$. Using (6) and $\left(6^{\prime}\right)$, the total variance of $\varepsilon_{t}$ is $\beta_{1}^{2} \sigma_{e, t}^{2}+\sigma_{\delta, t}^{2}$, where $\sigma_{e, t}^{2}$ is the conditional variance of the systematic shock, $e_{t}$, and $\sigma_{\delta, t}^{2}$ is the conditional variance of the unsystematic shock, $\delta_{t}$. Thus, for any month and portfolio, the proportion of the total variance of $\varepsilon_{t}$ that is attributable to the systematic shock, $e_{t}$, is $\left\{\beta_{1}^{2} \sigma_{e, t}^{2} /\left(\beta_{1}^{2} \sigma_{e, t}^{2}+\sigma_{\delta, t}^{2}\right)\right\}$, and the systematic risk (conditional variance) associated with holding that portfolio during month $t$ is

$$
\sigma_{\mathrm{SYS}, t}^{2}=\sigma_{\varepsilon, t}^{2}\left(\frac{\beta_{1}^{2} \sigma_{e, t}^{2}}{\beta_{1}^{2} \sigma_{e, t}^{2}+\sigma_{\delta, t}^{2}}\right) .
$$

Four estimates are required to use equation (7) to estimate the systematic variance of a portfolio for any month $t$. Estimates of $\beta_{1}$ and $\sigma_{\delta, t}^{2}$ are obtained by estimating regression (6). To economize on space, we do not report the results of estimating regression (6), but they are available from the authors upon request. Estimates of $\sigma_{\varepsilon, t}^{2}$ are obtained from the results of estimating regression (2). Estimates of $\sigma_{e, t}^{2}$ are obtained from the regression system used to estimate the systematic shock. This is either regression system (5), (2), or (3), depending on whether BILLRES, LBRES, or VWRES is used as the proxy for the systematic shock. For each portfolio, 
TABLE 7 Mean Treynor Ratios for Three Proxy Measures of the Systematic Shock to Bill and Bond Returns, Means Are for the Full Sample, All Peak Months and All Trough Months

\begin{tabular}{llcccccrr}
\hline \multirow{2}{*}{$\begin{array}{l}\text { Sample } \\
\text { Months }\end{array}$} & \multirow{7}{7}{ Portfolio } \\
\cline { 3 - 8 } & Proxy & Bill3 & Bill6 & Bond1 & Bond2 & Bond3 & Bond4 & Bond5 \\
\hline All & BILLRES & 1.51 & .93 & .74 & .48 & .41 & .41 & .30 \\
Peak & BILLRES & 1.76 & .97 & .61 & .25 & .12 & -.14 & -.15 \\
Trough & BILLRES & 1.11 & .69 & .57 & .44 & .42 & .43 & .34 \\
All & LBRES & 2.18 & .90 & .52 & .24 & .16 & .13 & .09 \\
Peak & LBRES & 2.47 & .97 & .43 & .14 & .05 & .01 & -.03 \\
Trough & LBRES & 2.20 & .91 & .53 & .29 & .25 & .21 & .17 \\
All & VWRES & 22.78 & 4.56 & 2.84 & 1.24 & .86 & .72 & .52 \\
Peak & VWRES & 37.95 & 6.40 & 2.92 & .75 & .19 & -.11 & -.29 \\
Trough & VWRES & 30.50 & 5.83 & 3.22 & 1.75 & 1.31 & 1.17 & .93 \\
\hline
\end{tabular}

the denominator of the Treynor ratio calculated for month $t$ is the estimated systematic standard deviation for that month. Thus, the ex ante Treynor ratio for month $t$ is

$$
\text { Ex ante Treynor ratio }=\frac{\hat{\mathrm{X}} \mathrm{R}_{t}}{\hat{\sigma}_{\mathrm{SYS}, t}} .
$$

The results of estimating monthly Treynor ratios are summarized in table 7. For each potential state variable, we report the mean ex ante Treynor ratio for each bill and bond portfolio over the full sample. In many respects, the results are similar regardless of the state variable chosen. For instance, for each state variable and portfolio, the mean Treynor ratios are larger than the Sharpe ratios, because the ex ante risk premium is the same as for the Sharpe ratio and the ex ante risk is smaller. For each state variable, the pattern across maturities for ex ante Treynor ratios is similar to that for ex ante Sharpe ratios, with ratios that are very high on the shortestmaturity bill and decline with maturity. Other than differences in scale, the only noticeable impact of state variable choice is that using either the longmaturity bond or the value-weighted stock portfolio exacerbates the differences across maturities while using the 1-month rate reduces the differences. However, even if the 1-month rate is used, the differences across maturities remain substantial. Table 7 also reports means of Treynor ratios during peak and trough months. Again, the pattern for each state variable is similar to that reported for Sharpe ratios. The business cycle analysis that we report for Sharpe ratios was repeated for all three sets of Treynor ratios. Results again are similar to those for Sharpe ratios and are not reported to save space. Like the corresponding ex ante Sharpe ratios, ex ante Treynor ratios on long bonds have a clear business cycle pattern.

The results reported in tables 6 and 7 provide a potential explanation for the fact that reward-to-risk ratios decline with maturity. The results 
in table 6 indicate that long-term bonds (bonds of maturity greater than 2 years) have a common source of systematic risk and the risk on any longterm bond is an effective proxy for that risk. Thus, the mean ex ante Treynor ratios based on LBRES for the Bond3, Bond4, and Bond5 portfolios are of similar magnitude (ranging from 0.09 to 0.16 ) and can reasonably be interpreted as estimates of the market price of long-rate risk. On the other hand, short-term bonds appear to have a second source of risk that is related to uncertainty in the 1-month bill rate and the 1-month bill rate appears to be an effective proxy for all of the systematic risk on the shortest-term portfolio, Bill3. Thus, the mean Treynor ratios for the 3-month bill that are based on BILLRES can reasonably be interpreted as estimates of the market price of short-rate risk (with sample mean of 1.51). Intermediate-maturity bills and bonds are exposed to both risks, so they have reward-to-risk ratios that fall between the two extremes. Thus, the differences between reward-to-risk ratios oflong-term and shortterm bonds do not necessarily imply that arbitrage opportunities exist in the market for U.S. Treasury securities. An alternative interpretation of the evidence is that there are two (or more) sources of systematic risk and differences in reward-to-risk ratios across maturities reflect differences in the prices of those risks. A precise identification of the sources of systematic risk is a challenge for future research; however, our results are suggestive. The business cycle pattern in returns to long-term bonds suggests that these returns are determined by expectations regarding the long-run strength of the economy. The fact that short-term bills and bonds are influenced by innovations in the 1-month bill rate suggests that another source of influence is the stance of current monetary policy. Results reported in Balduzzi et al. (2001) and Elton (1999) also support this conclusion.

\section{Sharpe Ratios and Modern Term Structure Theory}

In this section, we use simulations to examine the ability of modern term structure theory to reproduce the pattern of Sharpe ratios we find in the data. We focus our analysis on the class of models characterized by Duffee (2002) as essentially affine. The essentially affine class nests the completely affine class analyzed by Dai and Singleton (2000), which is the class of term structure models most extensively examined in the literature. Where completely affine models assume that the compensation for a risk factor is proportional to that factor's variance, essentially affine models allow compensation for risk factors to vary independent of factor volatility. Thus, the essentially affine framework is consistent with our empirical analysis in providing an opportunity to examine the implications of time varying risks and prices of risks.

The models examined in Duffee are classified with the notation, $A_{m}(n)$, where $n$ is the number of state variables and $m$ is the number of state variables that affect volatility. There is a trade-off in these models 
between the flexibility to model changing prices of risk and the flexibility to model changing factor variances. An $A_{0}(n)$ model allows the maximum flexibility in the specification of the price of risk but restricts factor variances to be constant over time. An $A_{n}(n)$ model allows the maximum flexibility to model changing variances but restricts the compensation for risk to be proportional to that factor's variance. Models with $0<m<n$ provide limited flexibility on both dimensions.

Duffee estimates $A_{m}(3)$ models because of evidence reported in Litterman and Scheinkman (1991) that three factors account for most of the variation in Treasury bond prices. He reports detailed results of parsimonious specifications of three $A_{m}(3)$ models. Duffee reports the essentially affine $A_{0}(3)$ model, because it does the best job of reproducing the behavior of expected excess returns. He reports a completely affine $A_{2}(3)$ model, because it is the completely affine model that does best at reproducing the behavior of expected excess returns. He reports the essentially affine $A_{1}(3)$ model to illustrate the trade-off between fitting conditional volatilities and excess returns.

For each model reported by Duffee, we used the following procedure to examine the ability of the model to reproduce the pattern of Sharpe ratios in table 2. First, we produced a pricing formula for each maturity discount bond for which we need a time series of returns. ${ }^{18}$ To do this, we substituted Duffee's parameter estimates into a system of four differential equations and used numerical integration to solve the equations for the coefficients needed to express the bond's yield to maturity as an affine function of the three state variables. Second, we simulated a time series of the three state variables using the state variable dynamics of the model. The length of each simulated time series is 466 months, which corresponds to the length of our historical sample period. Third, substituting the simulated values of the state variables into the pricing formulas produced the time series of yields that are used to calculate holding period returns for pure discount bonds that have the maturities reported in our table 2. Fourth, for each maturity bond, we repeated the methodology that we applied to historical data in Sections II and III of this paper. That is, we generated ex post Sharpe ratios using equation (1) and a time series of ex ante Sharpe ratios using equations (2) and $\left(2^{\prime}\right)$. We repeated the second through fourth steps 5,000 times for each model and report results of the simulations in table 8 . For each bond maturity, we report the mean and standard deviation of the 5,000 simulated ex post Sharpe ratios and the mean and standard deviation of the 5,000 mean ex ante Sharpe ratios.

For all three models, the standard deviations of the mean Sharpe ratios reported in table 8 are small relative to their respective means. Assuming

18. To generate bond returns, we need prices for both the maturity we are interested in and 1 month less. 
TABLE 8 Results of Simulations of Three-Factor Models of the Term Structure

\begin{tabular}{lccc}
\hline & \multicolumn{3}{c}{ Allowed Flexibility of Instantaneous Variances/Prices of Risk } \\
\cline { 2 - 4 } Maturity & Fixed/Flexible & Flexible/Fixed & Flexible/Flexible \\
\hline \multicolumn{4}{c}{ Means (Standard Deviations) of Simulated Ex Post Sharpe Ratios } \\
\hline 3 month & $.204971(.048456)$ & $.128900(.047220)$ & $.239182(.086996)$ \\
6 month & $.182710(.047715)$ & $.108555(.043398)$ & $.235763(.092503)$ \\
1 year & $.149578(.042942)$ & $.083748(.040039)$ & $.202236(.071262)$ \\
2 year & $.108986(.035691)$ & $.057061(.039980)$ & $.153947(.048805)$ \\
3 year & $.090051(.032170)$ & $.046933(.040362)$ & $.134486(.043410)$ \\
4 year & $.079535(.030171)$ & $.042915(.040281)$ & $.124669(.042260)$ \\
5 year & $.072306(.028794)$ & $.041149(.039921)$ & $.118164(.042490)$ \\
\hline & Means (Standard Deviations) of Simulated Ex Ante Sharpe Ratios \\
\hline 3 month & $.207775(.049277)$ & $.136127(.048444)$ & $.275843(.094101)$ \\
6 month & $.186287(.048802)$ & $.122781(.044560)$ & $.327683(.130242)$ \\
1 year & $.153518(.044219)$ & $.113032(.042542)$ & $.271721(.087607)$ \\
2 year & $.111798(.036747)$ & $.107078(.050190)$ & $.196554(.052923)$ \\
3 year & $.091943(.032993)$ & $.106269(.056914)$ & $.173411(.047214)$ \\
4 year & $.080888(.030827)$ & $.105210(.060667)$ & $.163842(.046997)$ \\
5 year & $.073320(.029331)$ & $.103183(.062453)$ & $.158979(.048535)$ \\
\hline
\end{tabular}

Note.-The models simulated are from Duffee (2002). The model classified fixed/flexible is Duffee's preferred essentially affine $A_{0}(3)$ model. The model classified flexible/flexible is Duffee's preferred essentially affine $A_{1}(3)$ model. The model classified flexible/fixed is Duffee's preferred completely affine $A_{2}(3)$ model. An $A_{m}(n)$ model allows $m$ of the $n$ state variables to affect the instantaneous standard deviations of state variables. All models are simulated 5,000 times.

that the true model that generates the term structure is characterized by standard deviations of similar magnitudes, our simulation results indicate that the small sample properties (for time series of 466 observations) of the methodology that we use to estimate the Sharpe ratios reported in table 2 are reasonably good.

In table 8 , the model labeled fixed/flexible is the essentially affine $A_{0}(3)$ model, which restricts factor variances to be constant but permits the maximum flexibility in estimating the price of risk. Of the three simulated models, this model is the most successful in replicating the table 2 pattern of Sharpe ratios across maturities. Our table 2 estimates for 3-, 4-, and 5-year bonds are within 2 standard deviations of the means produced by the simulated $A_{0}(3)$ model. Further, of the three simulated models, this model produces the mean ex post and ex ante Sharpe ratios that increase most dramatically as maturity shortens. However, the increase in Sharpe ratios as maturity shortens is far less dramatic than in table 2, and the mean simulated Sharpe ratios for maturities of 1 year and less are more than 2 standard deviations from the table 2 estimates. Moreover, this model does not replicate the differences between ex post and ex ante Sharpe ratios reported in table 2. This failure of the simulated model can be attributed to the fact that it permits no predictable variation in ex ante volatility, the denominator of the Sharpe ratio, due to the assumption of constant variances. 
In table 8 , the model labeled flexible/fixed is the completely affine $A_{2}$ (3) model, which permits flexibility in estimating changing factor variances but restricts the compensation for each risk factor to a fixed proportion of the factor variance. Because this model can reproduce some of the volatility clustering present in bond data, it provides predictable variation in volatility that produces ex ante Sharpe ratios that are higher than ex post Sharpe ratios for each maturity. However, the increase in Sharpe ratios as maturity shortens is less dramatic for this model than it is for the $A_{0}(2)$ model. Moreover, the $A_{2}(3)$ model produces a term structure of ex ante Sharpe ratios that is flatter than the term structure of ex post Sharpe ratios, which is contrary to the results reported in table 2.

The model labeled flexible/flexible in table 8 is the essentially affine $A_{1}(3)$ model, which permits limited flexibility in estimating both factor variances and prices of risk. This model captures aspects of both the $A_{0}(3)$ and $A_{2}(3)$ models. Sharpe ratios increase as maturity is shortened and ex ante ratios exceed ex post ratios for each maturity bond. However, like the other simulated models, the $A_{1}(3)$ model does not reproduce the extremely high Sharpe ratios for maturities of less than 1 year. An oddity of this model is that it produces a term structure of ex ante Sharpe ratios that exhibits a hump at the 6-month maturity.

Overall, the results reported in table 8 indicate that three-factor essentially affine models of the term structure capture important aspects of bond data. All of the models produce Sharpe ratios that change with bond maturity. Flexibility in modeling the compensation for risk appears to be a key element in reproducing the pattern of Sharpe ratios across maturities. Flexibility in modeling factor volatilities appears to be an important element in reproducing differences between ex post and ex ante Sharpe ratios. However, none of the models captures the extreme difference between Sharpe ratios on short-maturity and long-maturity bonds, because they do poorly at reproducing the high Sharpe ratios on shortmaturity bonds. Reproducing the high Sharpe ratios for short-maturity bonds represents a challenge for future term structure modeling.

\section{Conclusions}

Sharpe ratios on short-term and long-term bonds differ in fundamental ways. Sharpe ratios for short maturities are very high, for 3-month bills about 11 times the magnitude of Sharpe ratios on 5-year bonds. Sharpe ratios on long-term bonds are lower and, for maturities of more than a year, of a magnitude similar to those on common stocks. While Sharpe ratios on long-term bonds follow a business cycle pattern similar to that of Sharpe ratios on common stocks, Sharpe ratios on bills and short-term bonds exhibit no discernable business cycle pattern. These differences in Sharpe ratios for long and short maturities are consistent with Balduzzi et al. (2001) and Elton (1999), who conclude that short- and long-maturity 
bonds have different sources of systematic risk. If two (or more) factors determine the term structure, the prices of short- and long-bond risk need not be identical. So our results do not necessarily imply that there are arbitrage opportunities in the term structure. However, our simulation results indicate that the most widely used class of arbitrage-free multifactor models of the term structure does not replicate the high reward-to-risk ratios on bills. Reproducing the pattern of Sharpe ratios across bond maturities remains a challenge for future term structure modeling.

From an asset allocation perspective, our results indicate that Treasury bills and short-term Treasury bonds have some distinct advantages relative to long-term Treasury bonds. First, the reward per unit of bill risk is very high relative to the reward per unit of risk on long-term bonds. Thus, investors with the ability to do so can achieve superior combinations of risk and return by highly leveraged investments in bills. Second, the reward per unit of bill risk is independent of the business cycle. This differs from the reward to risk for long-term bonds, which is highest at business cycle troughs when investor access to funds may be limited. Third, bill risk is not strongly correlated with the risks on either long-term bonds or common stocks. Thus, bills provide diversification benefits not provided by other assets.

The advantages of bills must be balanced against one major disadvantage, the fact that the amount of risk associated with bill investments is small relative to the risks associated with bonds and stocks. Thus, the investor's ability to take advantage of the high reward-to-risk ratios on bills is limited by the investors' access to financial leverage. For some investors, high excess returns will be achieved only by taking on higher risk investments that have lower reward-to-risk ratios.

\section{References}

Balduzzi, P., E. J. Elton, and T. C. Green. 2001. Economic news and bond prices: Evidence from the U.S. Treasury market. Journal of Financial and Quantitative Analysis 36 (December): 523-43.

Bernanke, B., M. Gertler, and S. Gilchrist. 1996. The financial accelerator and the flight to quality. Review of Economics and Statistics 78 (February): 1-15.

Brennan, M., and E. Schwartz. 1982. An equilibrium model of bond pricing and a test of market efficiency. Journal of Financial and Quantitative Analysis 17 (September): 30129.

Campbell, J. Y. 1987. Stock returns and the term structure. Journal of Financial Economics 18 (June): 373-99.

Campbell, J. Y., and J. H. Cochrane. 1999. By force of habit: A consumption based explanation of aggregate stock market behavior. Journal of Political Economy 107 (April): 205-51.

Cochrane, J. H. 1991. Production-based asset pricing and the link between stock returns and economic fluctuations, Journal of Finance 46 (March): 209-37.

Cox, J. C., J. E. Ingersoll, and S. A. Ross. 1985. A theory of the term structure of interest rates. Econometrica 53 (March): 385-407.

Dai, Q., and K. J. Singleton. 2000. Specification analysis of affine term structure models. Journal of Finance 55 (October): 1943-78. 
Duffee, G. R. 2002. Term premia and interest rate forecasts in affine models. Journal of Finance 57 (February): 405-43.

Elton, E. J. 1999. Expected return, realized return, and asset pricing tests. Journal of Finance 54 (August): 1199-1220.

Fama, E. F. 1976. Inflation uncertainty and expected returns on treasury bills. Journal of Political Economy 84 (June): 427-48.

1990. Term structure forecasts of interest rates, inflation, and real returns. Journal of Monetary Economics, 25 (January): 59-76.

Fama, E. F., and K. R. French. 1988. Dividend yields and expected stock returns. Journal of Financial Economics 22 (October): 3-25.

- 1989. Business conditions and expected returns on stocks and bonds. Journal of Financial Economics 25 (November): 23-49.

. 1993. Common risk factors in the returns on stocks and bonds. Journal of Financial Economics 33 (February): 3-56.

Ferson, W. E., and C. R. Harvey. 1991. The variation of economic risk premiums. Journal of Political Economy 99 (April): 385-415.

French, K. R., G. W. Schwert, and R. F. Stambaugh. 1987. Expected stock returns and volatility. Journal of Financial Economics 19 (September): 3-30.

Glosten, L. R., R. Jaganathan, and D. E. Runkle. 1993. Relationship between the expected value and the volatility of the nominal excess returns on stocks. Journal of Finance 48 (December): 1779-1801

Gray, S. F. 1996. Modeling the conditional distribution of interest rates as a regimeswitching process. Journal of Financial Economics 42 (September): 27-62.

Hodges, C. W., W. R. L. Taylor, and J. A. Yoder. 1997. Stocks, bonds, the Sharpe ratio, and the investment horizon. Financial Analysts Journal 53 (November/December): 74-80.

Hodrick, R. J. 1992. Dividend yields and expected stock returns: Alternative procedures for inference and measurement. Review of Financial Studies 5 (Summer): 357-86.

Klemkosky, R. C., and E. A. Pilotte. 1992. Time-varying risk premia on U.S. Treasury bills and bonds. Journal of Monetary Economics 30 (August): 87-106.

Lauterbach, B. 1989. Consumption volatility, production volatility, spot-rate volatility, and the returns on Treasury bills and bonds. Journal of Financial Economics 24 (September): $155-79$.

Litterman, R., and J. Scheinkman. 1991. Common factors affecting bond returns. Journal of Fixed Income 1 (June): 54-61.

Longstaff, F., and E. Schwartz. 1992. Interest rate volatility and the term structure: A twofactor general equilibrium model, Journal of Finance 47(September): 1259-82.

Luttmer, E. G. J. 1996. Asset pricing in economies with frictions. Econometrica 64 (November): 1439-67.

Pesaran, M. H., and A. Timmerman. 1995. Predictability of stock returns: Robustness and economic significance. Journal of Finance 50 (September): 1201-28.

Sharpe, W. F. 1966. Mutual fund performance. Journal of Business 39 (January): 119-38.

- 1994. The Sharpe ratio. Journal of Portfolio Management 21 (Fall): 49-58.

Treynor, J. L. 1965. How to rate management of investment funds. Harvard Business Review 43 (January/February): 63-75.

Whitelaw, R. W. 1994. Time-variations and covariations in the expectation and volatility of stock market returns. Journal of Finance 49 (June): 515-41. 